\title{
EL PINTOR DIEGO A. DE CUENTAS
}

\author{
$\mathbf{P} \mathbf{R}$
}

\section{LEOPOLDO I. ORENDAIN}

A Manuel Romero de Terreros.

Narra el licenciado don Matías de la Mota Padilla en su Historia de la Nonquista de la Nueva Galicia, impresa en 1742, que en el convento de Santa Mónica de Guadalajara se veneraba una imagen de la Virgen María tallada sobre "piedra de metal", que tenía la particularidad de no advertirse "sino metal" si se le contemplaba de cerca, más alejándose de ella a la distancia de una "vara y media" se miraban, de vivos y variados colores, las figuras, ropajes y demás elementos que la compopian, circunstancia por la cual se conceptuaba como algo prodigioso. 1

1 En el capítulo Lxxxry de la obra citada dice Mota Padilla: "Se venera en dicho corvento una imagen de piedra de metal que don Nicolás Sedano sacó de una mina; es del tamafio de una sesma; déjase ver con túnica color de rosa, manto azul, corona abierta; la luna a los pies, mubes y resplandores la circunferencia; quenubines que la circumdan; tiene al manto sobre la cabeza, y en todo semejante a nuestra Sefiora de Guadalupe de Mírico y be diferencía en tener un nifio en la sinier- 
Deseando se analizara condición tan extraña, se acudió a la pericia de tres pintores para que examinaran la escultura, dictaminando después de lavarla, que no descubrian qué "mano de artífice alguno la hubiera pintado".

De los elegidos para llevar a término esa labor pesquisidora fueron Manuel Reinoso y Diego de Cuentas, quienes tomaron dibujos de la singular estatua por encargo del historiador de la Mota. Es de suponer que a las personas citadas se les reputara competentes en su oficio, ya que el encargo era de importancia; pero esto no obstante, nada se sabe de Reinoso de quien no existen noticias de su vida, ni rastro de sus obras; cuando menos en lo que hemos hurgado.

Cuentas, no pasa ignorado. Se conserva un buen acervo de sus producciones diseminado en iglesias, edificios públicos y colecciones particulares; mas este conocimiento está limitado a la ciudad de Guadalajara. Su nombre no se halla inscrito en las nóminas de los pintores coloniales y las pocas alusiones que de ell se han hecho, son en forma accidental. ${ }^{2}$

Ultimamente don Manuel Toussaint lo toma es consideración en su valioso libro El Arte Colonial en México calificándolo como "el artista más notable de la Nueva Galicia de principios del siglo xvir". Acertadamente dice que no puede afirmar haya sido tapatio, colocándolo "en este lugar, ya que sus pinturas tapatias son las más abundantes".

Efectivamente la cuna de Cuentas fué Acámbaro, en Guanajuato. Suponemos nació durante la penúltima década del siglo xvir debido a que la

tra mano, y otio rifio como que se abraza del cuerpo de la Seftora, quien parece le coje poniéndole la mano derecha sobre la cabeza; tiene de circunstancia que de cerca no se ve sino metal, más en distancia de una vara y media se registra su perfección: tres pintores se han puesto a dibujarla y todos contestan (por lo que no se duda), que han lavado la piedra, $y$ no se descubre que mano de artífice alguno la haya pintado."

"E1 Br. Dn. José Mascarelfas la llevó al Padre Feliciano (Pimentel) ha tiempo de veinticinco af́os, sacándola de poder de los herederos de don Nicolás Sedano... Y este año se guarneció curiosamente entre vidrieras con plata, por el Lic. don Diego Cervantes, y yo conservo en mi poder los fragmentos que quitaron a la piedra para guarnecerla y los dibrios que copiaron Diego de Cuentas y Manuel Reinoso, como que yo fuí quien por certificarme de si otros veían lo que yo, los mandé sacar. No fiscurro otra cosa de prodigio tan singular bastando ahora esta noticia que alguna vez podrh servir."

2 Don Abelardo Carrillo Gariet en stt obra Técnica de la pintura de Nuevo Espaifa, cita a Diego A. de Cuentas al ocupatse de las advocaciones religiosas e imagenes preferentemente ejecutadas por los pintores de la colonia. 
más antigua de sus obras data de 1709. Descendia de españoles, siendo hijo natural de don Juan Martínez de Alencaster y doña María de Sandoval y Gamboa; asi lo confiesa en su testamento. Esto aclara el significado de la inicial " $A$ " que anteponía a su apellido, y que corresponde a la primera letra del segundo de su progenitor.

Contrajo matrimonio con doña Teresa Patiño, de quien enviudó dejándole cuatro hijos: Diego, Gertrudis, Rosalía y Juan Antonio. Residió avecindado en Guadalajara, como lo declara, debiendo haber sido por muchos años, porque el ciclo de sus pinturas que conserva la ciudad, abarca de 1709 a 1737, o sea siete años antes de su muerte acaecida el 18 de marzo de 1744.

El 28 de septiembre de 1743 , confirió poder para testar a favor del bachiller don Lorenzo José Buitrago, al cual le tenia comunicados sus negocios de conciencia; le designó como albacea encomendándole cumpliera sus últimas disposiciones.

Como los únicos documentos que hemos podido hallar son el acta de defunción y su testamento, la primera en uno de los libros del archivo dei Sagrario Metropolitano de Guadalajara, y el segundo en el protocolo del Escribano Real don Alejo de Santa María Maraver, nada podemos afir. mar fuera de lo que en estos papeles está escrito. ${ }^{3}$

3 EI acta de defunción la contiene el "Libro xvir donde se asientan las personas que mueren en esta Ciudad de Guadalajara y comienza a correr desde el 22 de abril dia en que se llenó el libro antecedente del año de 1730, siendo Cura Rector de este Sagrario el señor doctor don Pedro Padilla, Provisor y Vicario General de este Obispado".

El número actual de dicho libro es D. 1730/45. El acta dice asi : Al margen: Diego de Cuentas, Espafiol. Viudo. Dentro: "En Guadalajara a 18 dias del mes de marzo de 1744 falleció y se le dió septultura eclesiástica en la iglesia de San Agustín a Diego de Cuentas espafiol, viudo de Teresa Patiño. Recibió los Santos Sacramentos, se le cantó misa en el Sagrario de ésta Iglesia Catedral y testó por poder que dió ante don Alejo Maria Maraver Escribano Real a los 24 de Septiembre de 1743, al Bachiller don Lorenzo Buitrago Presbitero a quien nombró albacea y por herederos a Diego, Gertrudis y Rosalía de Cuentas sus hijos legítimos, mandó se den las mandas forzosas a dos reales y para que conste lo firma: Ldo. Joseph Reyes Gómez de Aguilar, Xavier Gómez de Guerra."

Las partes medulares del testamento escrito en el protocolo del escribano Maraver que se guardan en el Archivo de Instrumentos Públicos del Estado de Jalisco dicen: "Yo Diego de Cuentas y Alencaster, vecino de esta ciudad de Guadalajara, hijo natural de don Juan Martínez de Alencaster y de donia Maria de San. doval y Gamboa, difuntos, vecinos que fueron del pueblo de Acámbaro de donde soy originario, estando enfermo en cama de enfermedades que Dios Nuestro Señor 
Por tradición se sabe que tenía taller establecido en una accesoria del convento de San Agustín, aseveración que tiene fundamento porque pidió que al fallecer, se sepultara su cuerpo en la iglesia de dicho monasterio donde tenia "entierro en el altar de las Animas".

Como a fines del siglo xvit trabajaron en la capital del teino un buen núrnero de pintores, algunos excelentes, nos imaginamos que al despuntar sus años mozos, Cttentas, impulsado por su vocación, fué a tomar cátedras en alguno de los talleres hasta obtener el rango de maestro pintor, de conformidad con lo que mandaban las ordenanzas. Estas exigian "que

ha servido enviarme, en mi entero juicio... y teniendo comunicadas todas las cosas de mi conciencia con el Bachiller don Lorenzo José Buitrago Presbítero... doy poder... quiero que... cuando fallesca se sepulte mi cuerpo en el altar de las Animas, y aquel dia y siguientes se the cante misa de cuerpo presente acompañando la Cruz Alta de la Sta. Iglesia Catedral, Cura y sacristán... fui casado y velado según el orden de Nuestra Madre Iglesia con dona Teresa Patifio, difunta y durante nuestro matrimonio tuvimos y procreamos por nuestros hijos legítimos a Diego, a Gertrudis, a Rosalia y a Juan Antonio que hoy es difunto que dejó por su único hijo legítimo a Francisco de Cuentas, mi nieto... hecho en la ciudad de Guadalajara en 28 dias det mes de septiembre de 1743, siendo testigos pagados y llamados Lorenzo y Agapito Martinez y Antonio de Annaral presente y vecinos. Firmas: Diego A. de las Cuentas."

4 El dato consignado to dio al que esto escribe Ixca Fatias, quien aseguraba que había existido otro pintor Cuentas de notmbre Ramón. Lo último es inexacto, y lo supo posiblemente, por lo que asegura Fernández Villa referente a que don Nicolís León encontró un manuscrito del Canónigo $J$. Guadalupe Romero concebido én estos téminos: "Ramón Cuentas, nació en Guadalajara y fút discipulo de Cabrera en México en donde vino para aprender el arte de la pintura al lado de tan hábil artista, permaneciendo a su lado por el espacio de 10 años, volviéndose a Guadalajara donde estableció un obrador. Hizo muctias pinturas para los conventos quedando un magnífico y grande cuadro de Nuestra Señora subiendo a los cielos acompafiada de muchos grupos de Angeles que existe en la sacristia de la Merced. Esta pintura aś como las otras que dejó son muy recomendadas por los inteligentes. Murió en Guadalajara." En tal manuscrito el señor Romero cambió el nombre del pintor sin que pudiera alegarse que un Ramón fuera hijo de Diego. El cuadro de la Merced ostenta con grandes caracteres la palabra Didactus, por lo cual no da lugar a confusiones. Lo de ser originario de Guadalajara queda descartado por an testamento. Qde estudió México, no el dudable; pero si absurdo pretender que con Cabrera, que nació en 1695 y llegó a la capital del virreinato para ingresar al taller 'de Juan Correa en 1730, o sea 21 años despué que habia pintado Cuenta: a mural de la Merced. 
se sepa preparar lienzos, telas y láminas, que conozca dibujo, escorzos, colores, trapos sueltos y combinados, sombras, medios tonos y obscuros"."

Nuestro artista satisfizo tales condiciones, pues de otra suerte, no habria podido obtener el título con el cual se le denomina en un avalúo, del cual hablaremos más adelante, trabajo prohibido a quienes no eran "maestros examinados".

Tocóle actuar durante la época de transición que experimentó el arte colonial del ciclo del barroquismo al del murillismo, puesto a tono por Estrada, Cabrera y sus seguidores. Influenciado por esta circunstancia, Cuentas, deja marcados dos aspectos en sus obras. Las de su iniciación tienen el sello de las producciones pictóricas de finales del seiscientos, cuando "pasó la pintura de un naturalismo carnal y frenético, a un realismo turbulento, a un colorido fastuoso, al paganismo dinámico del barroco, que llegó a la Nueva España con los cuadros y grabados de Rubens". *

Posteriormente modifica su técnica, tomando el camino que trazan los innovadores; da a sus cuadros amaneramiento, sentimentalismo, abandona los colores sobrios por los tiernos, torna dulzonas las caras, imprime suavidad a las figuras, entona de carmín las mejillas $y$ sonrosa las carnes.

A guisa de hipótesis diremos que a su taller vinieron a demandarle que pintara a la manera que estaba en boga y era tan estimada, e impelido por ese apremio, retornó a la capital para adiestrarse en el atrayente estilo. Esto pudo haber acaecido de 1718 a 1720 ; lapso en que no hay nada suyo fechado en Guadalajara, y sí en México, estando en La Profesa cuatro óleos ( $1.05 \times 0.86 \mathrm{~m}$.) que representan a los Evangelistas, datados en el último de los años citados.

De estos cuadros, el señor Toussaint escribe que "revelan maestria en su arte $y$ vigor en el toque, acaso remembranzas de la pintura de nuestro siglo xvir".

En 1723, ya está de regreso en la Nueva Galicia, porque en diciembre se le comisiona "como maestro de Pintura" para valuar un lote de objetos artísticos que dejó al morir, el 10 de junio de ese año, don Ginés Gómez de Valdés, padre de don Juan Leandro Gómez de Parada, Obispo de Yucatan, de Guatemala, y por último de Guadalajara.

Cuentas formó un inventario detallado de las piezas tasándolas. Figuraban en él espejos, pinturas, biombos, más sesenta y seis láminas y

5 Manuel Tougsaint. El Arte Colonial an Mérico. 1948.

6 Agustín Velázquez Chávez. Tres Siglos de Pintura Colomial Mericana. Méx. 1939. 
lienzos a los que da un valor de $\$ 226.00$, totalizando el conjunto en $\$ 310.00{ }^{7}$ Cada pintura la estimó entre tres y cinco pesos, pareciendo quimérico aceptar que alguien pudiera subsistir del fruto de su ingenio con ese mal pagar.

En la segunda etapa de su carrera, deja de usar su firma acostumbrada sustituyéndola por un jeroglífico, claro y expresivo por otra parte, consistente en una serie de cuentas, corno las de un rosario, a las que ar̃a-

7 Este dato lo debo a la gentileza de mi fino amigo don Manuel Romero de Terreros a quien por medio de estas líneas reitero mis agradecimientos. El documeato que obra en su poder está concebido en estos términos:

"Ginés Gómez de Valdés. Inventario, 9 de diciembre de 1723. "Diego de Cuentas, Maestro de pintor valub:

"12 paises de hermitaños (sic) de vara y cuarta de largo por vara de ancho $\$ 36.00$.

"12 lienzos de la fama de dos varas y cuarta de largo y una tercia de ancho $\$ 60.00$.

"12 lienzos de Apóstoles de vara y cuarta de largo y vara de ancho $\$ 36.00$.

"6 dichos de Vírgenes de dos varas y cuarta de largo y una cuarta de ancho $\$ 30.00$.

"14 láminas con sus marquitos de granadillo de a cuarta $\$ 4.00$.

"Otra dicha de limeneatura con cerco dorado de Nuestra Señora de los Dolores de una tercia de largo $\$ 6.00$.

“Otra de Santa Catarina del mismo tamaño y marco dorado $\$ 3.00$.

"Dos dichas de San José y Nuestra Señora del Pópulo con sus marcos de granadilio $\$ 6.00$.

"Lienzo de vara y tercia de largo y vara de ancho de la cabeza de San Juan $\$ 5.00$.

"Ĺ́mina de San Nicolás Tolentino de dos tercias de largo y media vara de ancho con marco de granadillo $\$ 15.00$.

"Nuestra Señora de la Concepción de dos varas y media de largo y una y media de ancho $\$ 6.00$.

"Dos espejos, las lunas de a tercía y en sus marcos negros $\$ 16.00$.

"Ntra. Sefiora de Belem de vara y cuarta de largo y una de ancho $\$ 5.00$.

"Lienzo de San Miguel de vara y cuarta de largo y una de ancho con marco dorado $\$ 5.00$.

"Dos dichos de San Jorge y Santiago de vara y cuarta de largo y una de ancho $\$ 9.00$.

"Un Crucifijo de marfil en su cruz de granadillo de una tercia $\$ 8.00$.

"Un biobo (sic) de pintura fina de doce varas, bien tratado, en $\$ 20.00$.

"Otro dicho de diez tablas $\$ 15.00$.

Un rodastrado, pintura de China, de 12 tablas $\$ 25.00$." 
de la palabra "fecit". Asi se ve un Apostolado del convento de Zapopan, 8 en una Divina Pastora que tiene el sello que Páez dió a las suyas; en un Arcóngel de facciones femeninas y en un Santo Sentor Santiago, estas pinturas en poder de particulares.

La obra de Cuentas gitó también en torno del retrato, faceta en que se apegó a la pauta consagrada en la iconografía colonial presentando a sus personajes con los atributos clásicos: mesa, cortina escudo y cartela. Pintó a los señores obispos Juan Sánchez Duque, Santiago de León Garabito, Nicolás Gómez de Cervantes, Francisco Gómez de Mendiola y fray Felipe Galindo, óleos que están en la Sala del Cabildo de la Catedral tapatía, menos el último que adorna la escalera del Museo de Guadalajara, antiguo Seminario de San José fundado por el señor Galindo.

Es probable que sean hechura suya otros cuadros de la galería altudida, debido a la analogía que manifiestan algunos de ellos, pero como las cartelas están repintadas, sitio en que habitualmente escribía su nombre, quizás se encuentre debajo de las leyendas sobrepuestas.

Por otra parte, estos trabajos no los hizo en vida de log personajes, sino que le fueron encargados para legar a la posteridad un recuerdo de la semblanza y catadura de los prelados que hablan regido la diócesis de Guadalajara, inspirándose en efigies ejecutadas con anterioridad. Apoyamos esa presunción en dos lienzos que hizo Cuentas del señor Obispo Mendiola, muerto en 1576 . Uno lo presenta en traje de oidor fechado en 1714 ; otro es de 1731 y se manifiesta con 109 arreos de su dignidad. En ambos, las facciones del rostro son copias de un óleo antiguo, que sỏlo tiene valor doctumental, de autor anónirio, que conserva la Catedral.

En la misma basílica está un retrato del padre Feliciano Pimentel al que supo imprimirle carácter, y a nuestro juicio, es el de más mérito. Siendo Cuentas contemporáneo de este venerable varón captó los rasgos fisonómicos trasladándolos a la tela en 1733. La figura del jesuita se destaca de un fondo oscuro, como oscura es la sotana La cara larga, huesosa, de asceta, el cabello cano, las facciones enérgicas, los ojos vivos, las cejas negras y las sienes hundidas, dan al todo realismo, a la vez que fuerza, de-

8. Dada la medida de estos doce curadros $(1.07 \times 0.76 \mathrm{~m}$.) no es difícil que sean lo mismos que se listan en el inventario del señor Gómez de Valdez.

9 El tamaño de estos retratos es de $2.10 \times 1.26 \mathrm{~m}$. centimetros más o menos, excepto el del sefior Galindo en el Museo que mide $2.24 \times 1.25 \mathrm{~m}$. 
notando cómo este sujeto fué capaz de realizar todas las obras y reunir los merecimientos relatados en la elocuente cartela. ${ }^{10}$

Independientemente de estos retratos, en el Museo Michoacano hay uno de buen tamaño de don Vasco de Quiroga que primitivamente era del Colegio de San Nicolás. Contiene larga leyenda latina que abarca nueve renglones de la parte inferior de la tela, la que en opinión del señor Toussaint es mediocre. Este destacado crítico lista también otro "cuadro bastante aceptable" que está en el Museo de Pintura del Colegio de Zacatecas firmado en 1730 , y representa al fray. José Guerra.

Por ser obras aisladas, indudablemente las mandaron hacer al taller del pintor en Guadalajara, por recomendación de lo que laboró para la galería de la Catedral.

Salvo mejor parecer su obra más importante es el mural que existe en el templo de la Merced, fechado en 1709. Representa "la descensión de la Madre Santísima de la Misericordia para declarar sus intentos a San Raimundo de Peñafort, San Pedro Nolasco y el rey don Jaime de Aragón sobre la fundación de tan esclarecida orden de redención de cautivos". 11 Cuentas manifiesta aqui plenamente sus aptitudes para los trabajos monumentales con todo el impetu de la juventud.

Cubre este cuadro la totalidad de la pared poniente de la sacristía de la dicha iglesia tapatía, siguiendo la curvatura de la bóveda. Mide 7.83 metros de largo por 5.47 de alto. En el centro medio superior colocó a la Virgen llevando como fondo a la Santisima Trinidad, flanqueada de ángeles cantores y músicos que tañen arpas, bandolines y otros instrumentos. A la derecha hay tres santos mercedarios cuyos blancos hábitos ostentan grandes caídas de paños; los acompañan otros tantos jóvenes en actitud orante. Al lado opuesto está igual número de santas de la misma or-

10 Mide también este retrato $2.10 \times 1.26 \mathrm{~m}$. y la cartela tiene escrito esto: "Retrato del Venerable Padre Feliciano. Pimentel de la Compañía de Jesís, profeso de cuarto voto, natural de la Ciudad de San Luis Potosi, quien leyó el primer curso de artés en este colegio de Guadalajara y después morador de él treinta y ocho años en curo tiempo fué Rector dos veces y despuśs Prefecto de la Congregación de la Anunciata más de veinte afios. Patrón y fundador insigne a expensas de su solicitud y celo dei Convento de Sefioras Religiosas Agustinas Recoletas de Santa Mónica de esta Ciudad, quien murió en este Colegio de Guadalajara a los setenta y dos años de su edad y cincuenta y siete de su Religión día nueve de abrif en que celebra la Iglesia Nuestra Madre la traslación de la gloriosa Santa Mónica el año de 1733. Didacus a Cuentas F. a 1733."

11 Fray Luis de Palacio. Nuestra Sextora de Zapopan. 
den, asistidas por ángeles erectos que empuñan los atributos que la iconografía religiosa les tiene asignados. Estos grupos descansan sobre nubes, que vienen formando el techo de las escenas que desarrollan en la parte inferior.

Aquí colocó al centro a San Pedro Nolasco, a Raimundo de Peñafort, después santo, y al rey don Jaime de Aragón; el primero con vestiduras eclesiásticas, los otros, con traje de corte. A la derecha del espectador se ve la administración del viático a San Ramón Nonnato quien lo recibe de manos de Nuestro Señor Jesucristo, revestido de alba corta y capa pluvial, asisticlo por varios ángeles. En la parte izquierda está San Pedro Pascual cuando lo asesina un sarraceno, quien con mano airada clava un puñal en la nuca del santo. Hay un ángel al pie del altar junto a la mitra del celebrante, otro vuela sosteniendo una corona de flores y la palma del martirio. Completa este pasaje un gracioso infante hincado de rodillas en la última grada. Viste traje de noble, lleva rizada peluca, y parece muy ajeno al terrible drama que ante él pasa. Esta criatura es una representación del Niño Jesús. Está con los pies descalzos, las manos en actitud orante teniendo impresos los estigmas de los clavos en dichas extremidades. Por los intercolumnios se deja ver un paisaje florido; montes, lagos y ríos que se desprenden en cascadas al estilo echaviano. Las columnas del lado derecho, de estilo salomónico, labradas a lo barroco, son semejantes a las de la portada de Santa Mónica, templo edificado por aquella época, y en donde tuvo el pintor entenderes porque alli estaba la Virgen de piedra metal, y el padre Pimentel era benefactor del convento. En un costado del altar, lado del Evangelio, anuncia una cartela: "A devoción de los pobres de esta Ciudad." Ia firma está en la segunda grada "Didacus $A$. Cuentas F. Año 1709'.

En contraste con esta obra mayúscula tenemos en el Museo de Guadalajara una lámina de cobre de sólo $52 \times 42$ centimetros, en la que Cuentas hizo una $V$ irgen del Apocalipsis. Contiene varias figuras: La Virgen alada que levanta en alto al Niño; el Padre Eterno; San Miguel que espada en mano combate al dragón de múltiples cabezas que se enrosca contra un globo sobre el que está colocada la imagen de la Señora; San Juan Evangelista que contempla la visión asentado en un campo donde el pintor reproduce los árboles y verdores de sus fondos. Todo esto lo desarrolló con gran sentido detallista.

Algo similar tocante a fondos lo tenemos en un $\operatorname{San}$ Juan Bautista, propiedad del que esto escribe, firmado sin fecha. Mide $1.83 \times 1.04$ 
metros. El Precursor se mira de cuerpo entero acariciando con la mano izquierda un cordero, y sosteniendo a manera de cayado con la derecha, una cruz de caña en la que se enlaza una filacteria con la frase "Ecce Agnus Dei".

Pintó un San Miguel Arcángel (1.90 × $1.05 \mathrm{~m}$.) ataviado a la romana llevando en la diestra un cetro, y apoyando la mano izquierda sobre el pomo de una espada, y una Sagrada Familia fechada en 1711 , de $2.43 \times$ $1.75 \mathrm{~m}$. Contiene las imágenes de San Joaquín, Santa Ana, San José, la Virgen, el Niño Jesús y el Padre Eterno, con ángeles sobre nubes, más el Espíritu Santo que baja en forma de paloma, llevando en el pico una corona de espinas. Ambas pinturas son de la colección de la señorita Severa Rivas.

De 1714 existe en el Santuario de Guadalupe un San José con agradables vestiduras floreadas de múltiples tonos $y$ toques dorados, el que adorna la sacristía. Estả restaurado de manera imperfecta, y al colocarlo adosado a la pared empastaron la superficie de la tela buscando igualarla con la del muro deteriorándola.

Conserva la basílica de Zapopan, ađemás de los doce apóstoles antes citados, un Martirio de San Bartolomé, bleo de $1.84 \times 1.25$ metros, de la buena época del pintor, ejecutado con realismo. Un verdugo desuella el brazo izquierdo del apóstol mirando al espectador con aire de saña; a otro compañero de oficio lo colocó al lado opuesto inclinándose en un acertado escorzo.

Mandaron del Museo de Guadalajara, al naciente de Tepic, una $V$ irgen con Angeles, ${ }^{12}$ reservándose aparte de los óleos a que ya hemos aludido, otros tres que son: Un San Juan de la Crus; ${ }^{18}$ una Purisima y La Trinidad con los Arcingeles. ${ }^{14}$ Los dos últimos son de los postreros trabajos del artista llevando impresa la influencia cabreriana por los toques rosados en las carnes y lo amanerado de la composición, denotando marcada decadencia en comparación con sus anteriores producciones, aun cuando rememora sus años idos con los fondos de campo verde-azules que le son tan peculiares.

12 Firmado en 1732. Mide $1.88 \times 1.25$ metros.

13 Oleo sobre tela de $1.09 \times 0.84$ metros Firma: "Didacus a Cuentas Fet."

14 La Purísima está firmada en 1789, y en 1737 La Trinidad, midiendo esta tela $1.54 \times 2.14$ metros. 
La Trinidad es una composición al estilo mexicano. Los tres personajes tienen la misma fisonomía, igual edad, apartadas completamente de la iconografía religiosa admitida eclesiásticamente. Al centro sentó al $\mathbf{H i}$ jo, a su izquierda al Padre, con luengas barbas en una cara lozana; el Espíritu Santo queda a la derecha. Aquí resalta lo que influyó la escuela de Cabrera, quien puso en boga este misterio en la forma expresada. Cuentas lo remeda olvidándose de lo que veintiocho años antes hizo en su Sagrado Familia y en el mural de La Merced, cuyas Trinidades evocan correctamente a la tercera persona con la simbólica paloma.

No pretendemos que la catalogación de las pinturas de Diego $A$. de Cuentas, o De las Cuentas, como firma en su testamento, sea completa; se podrán hallar más, pero si cabe afirmar que las que haya diseminadas en el país no superan al número de las que tenemos en Guadalajara; cantidad suficiente para que al autor se le titule tapatio, pese a su origen guanajuatense, ya que largos años de su vida transcurrieron morando en esta ciudad y en ella forjó su obra. 
DOI: http://dx.doi.org/10.22201/iie.18703062e.1951.19.520

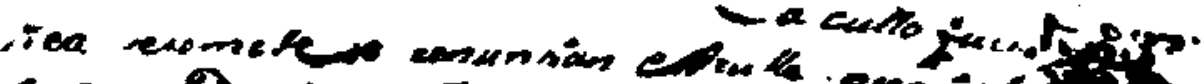

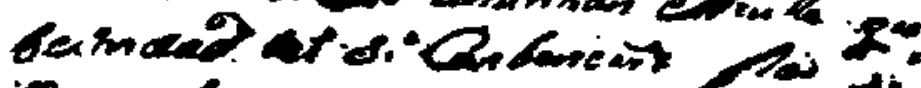

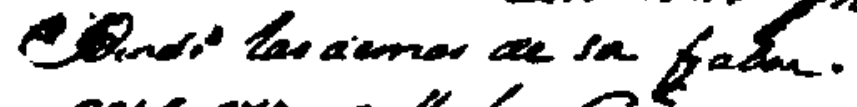

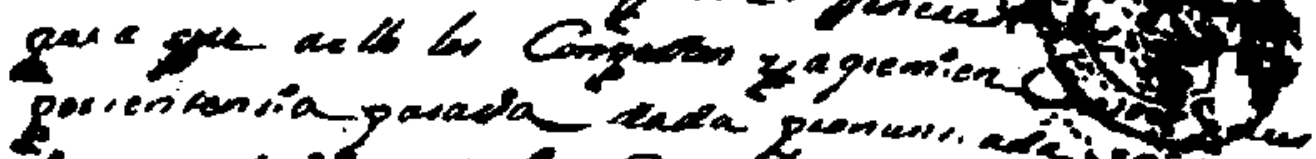

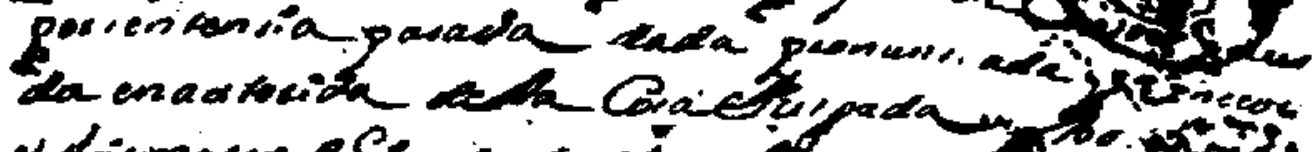

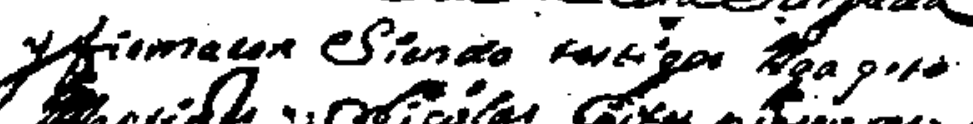

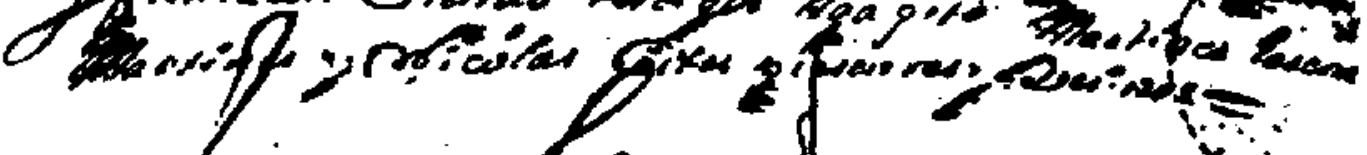

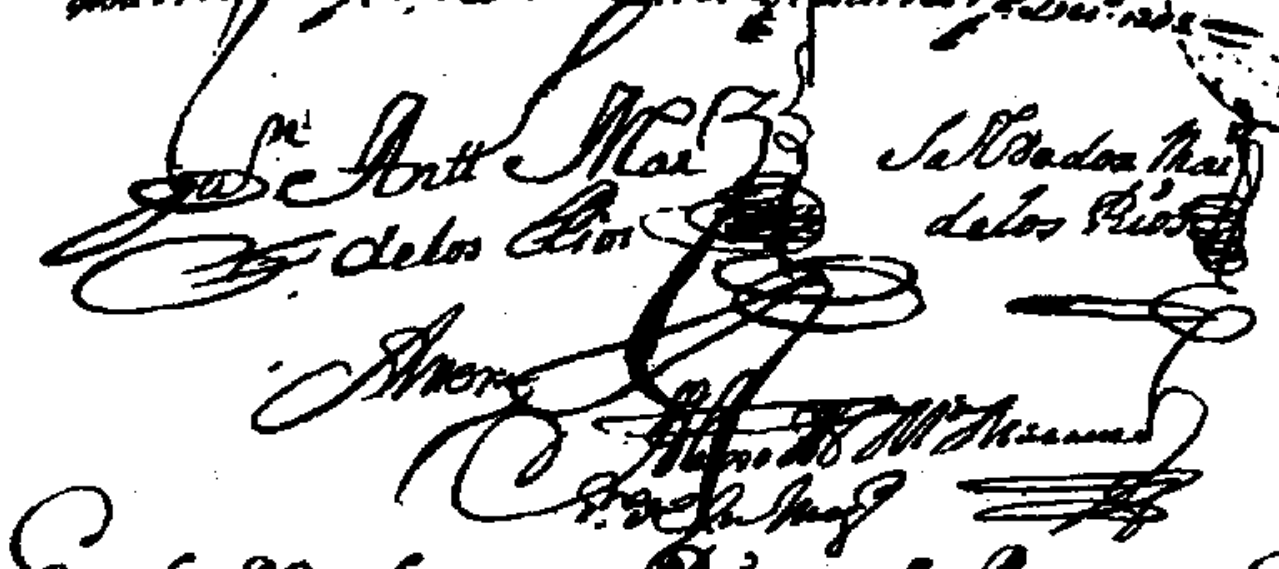

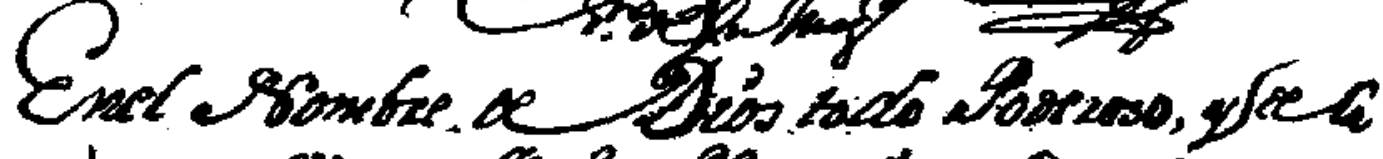

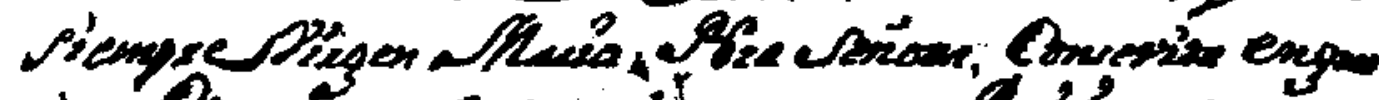

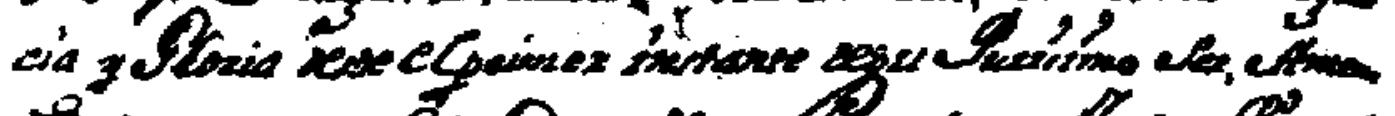

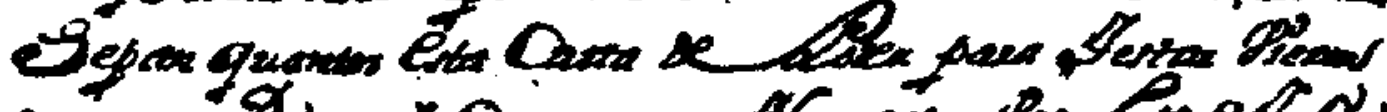

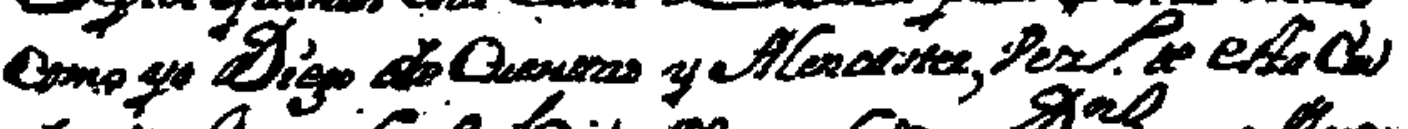

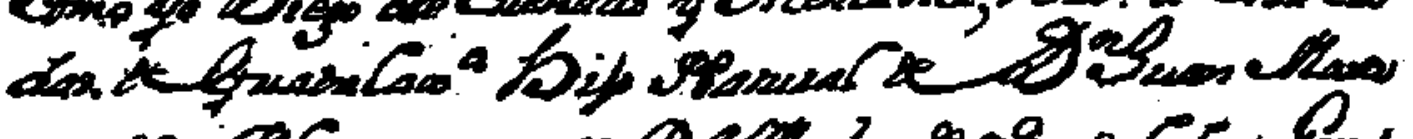

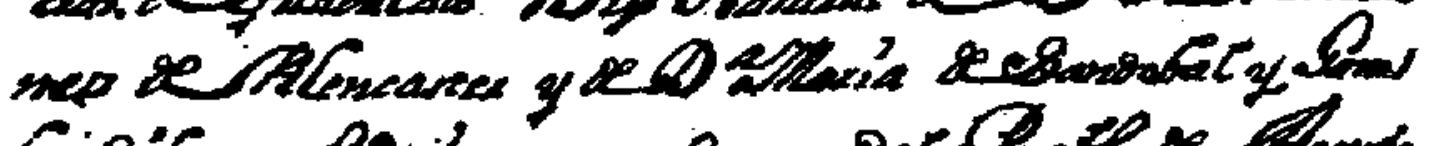

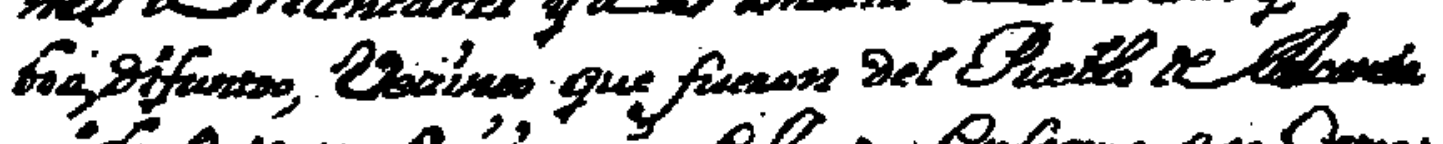

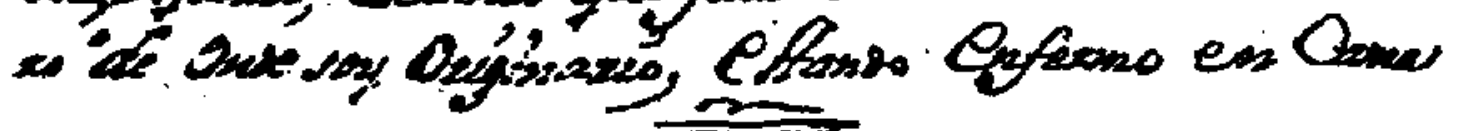




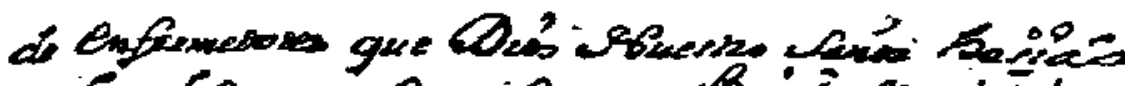

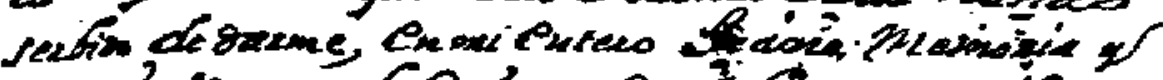

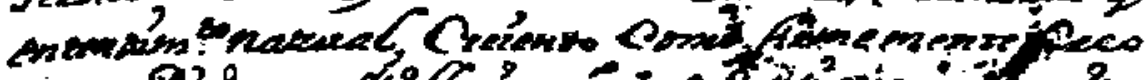

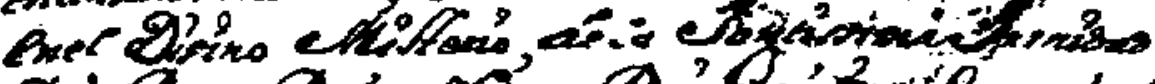

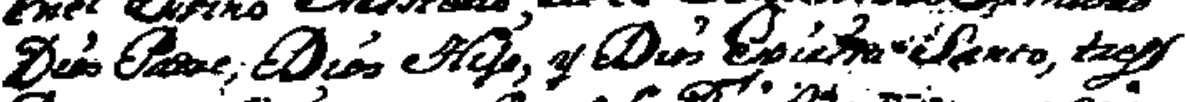

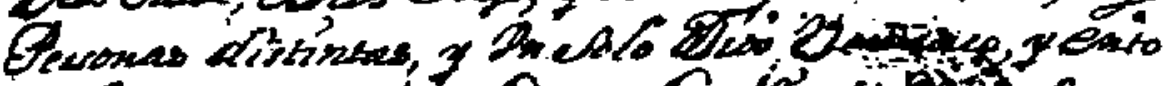

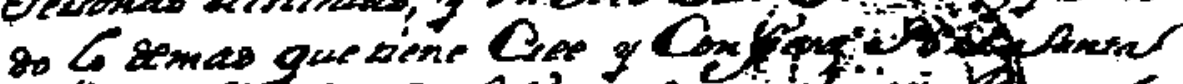

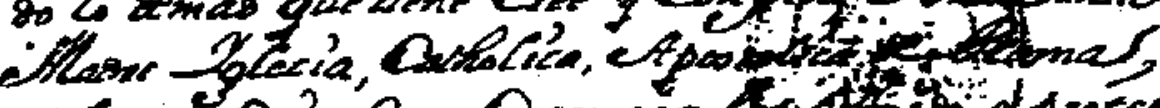

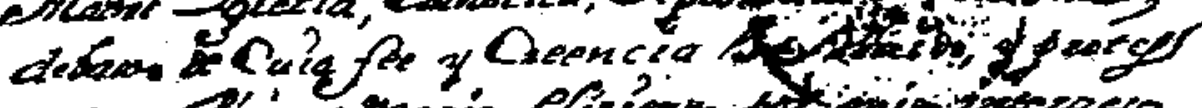

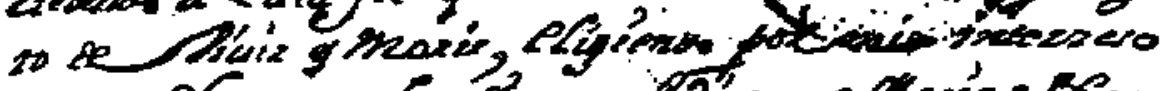

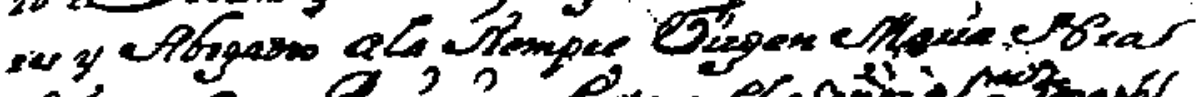

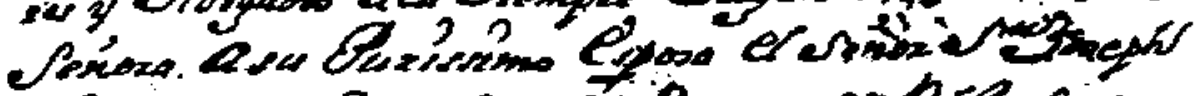

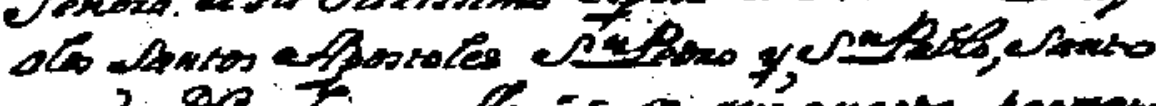

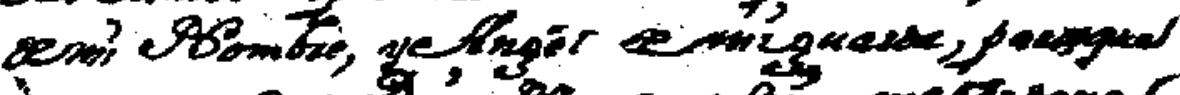

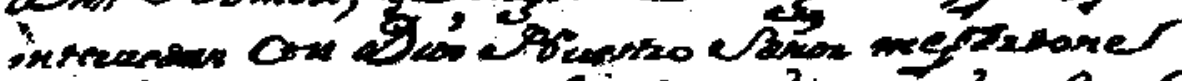

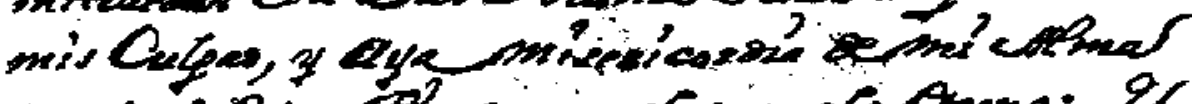

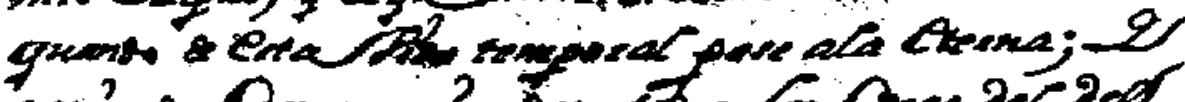

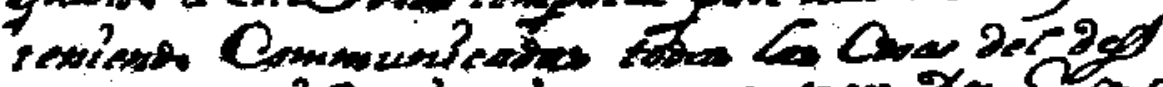

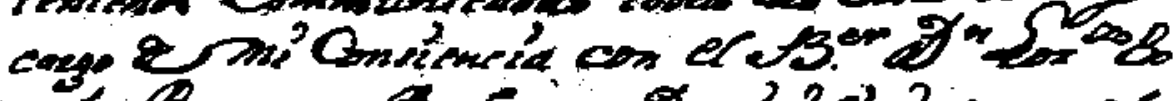

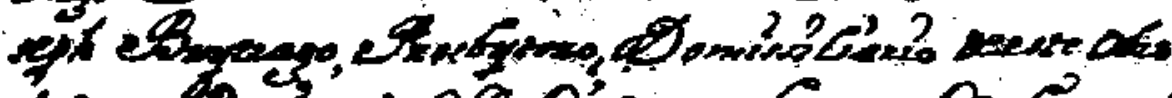

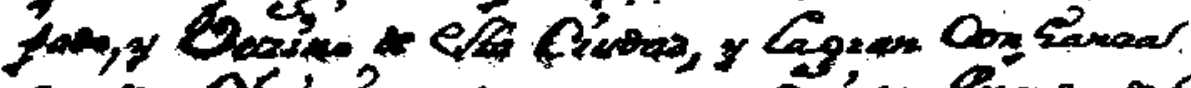

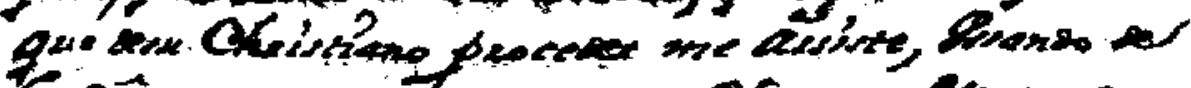

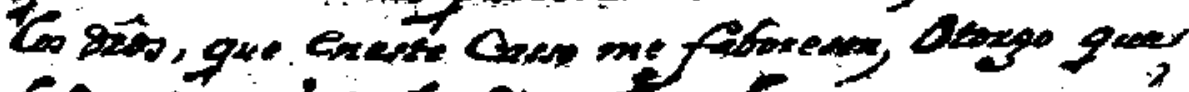

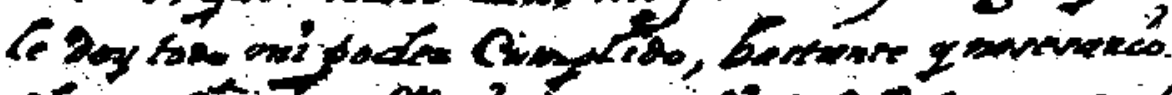

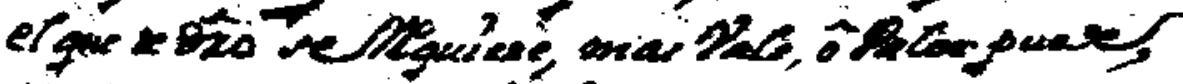

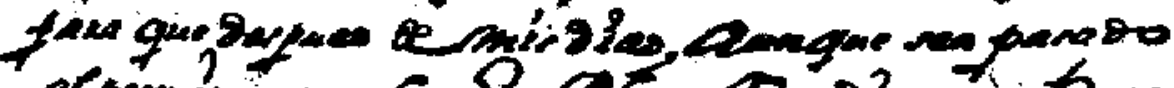

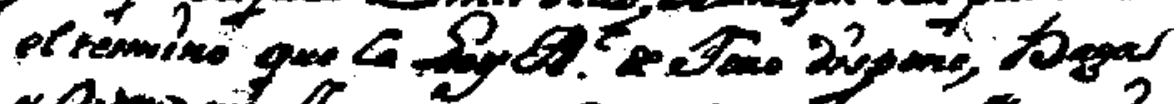

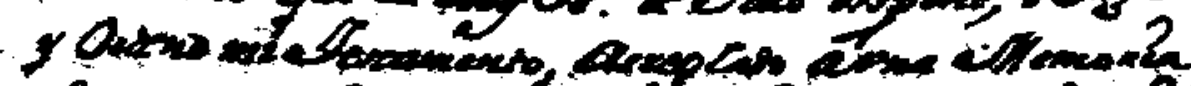

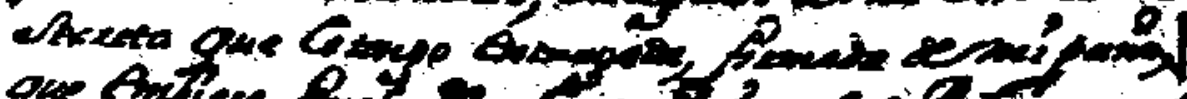

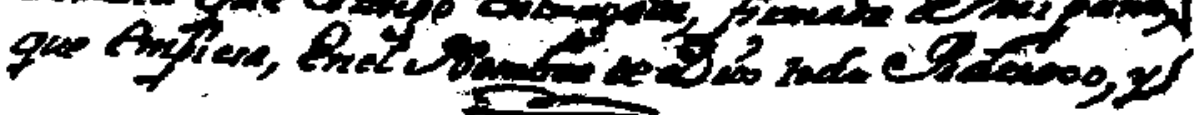


arome

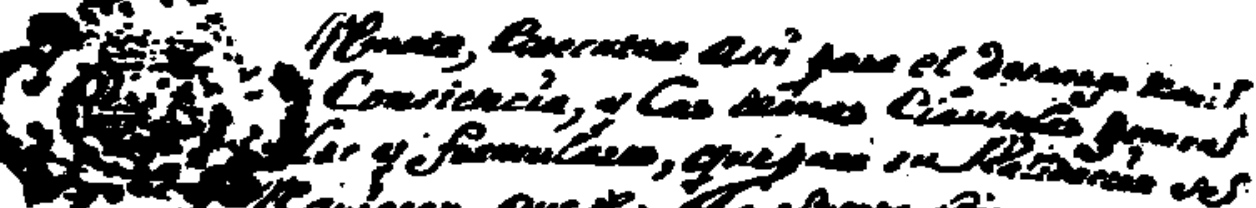

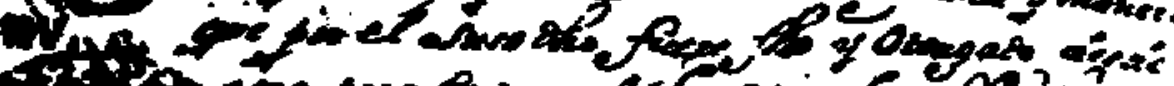
4:

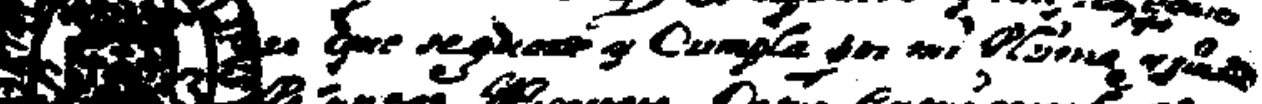
a

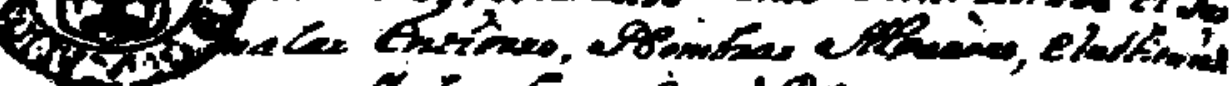

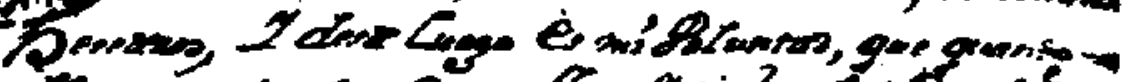

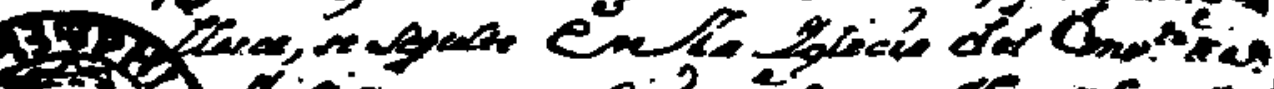

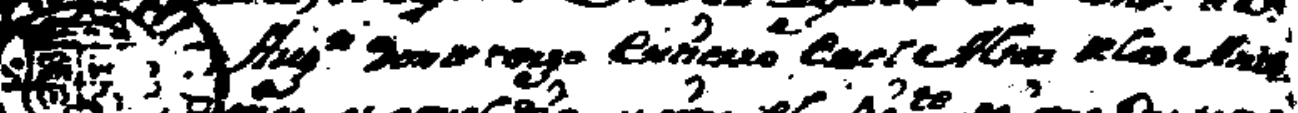

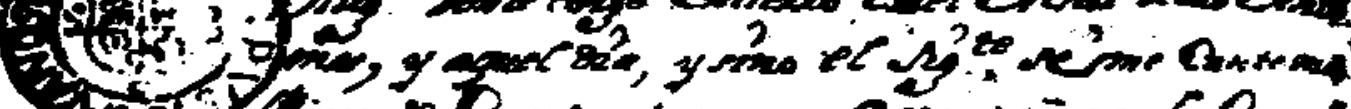

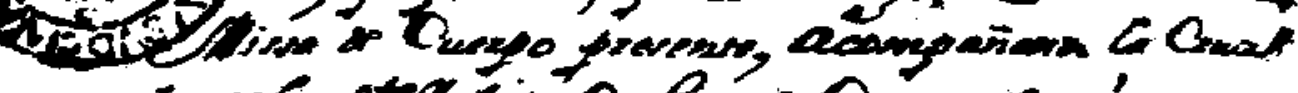

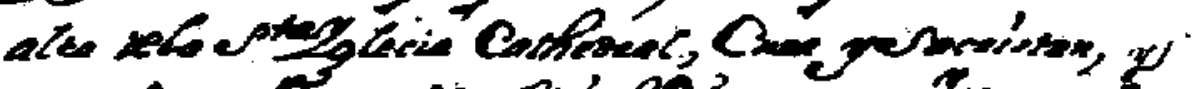

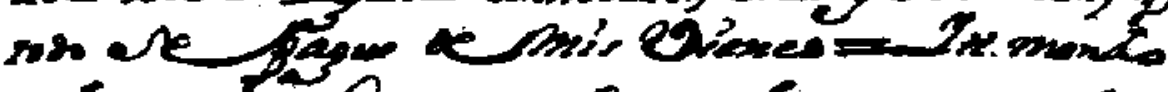

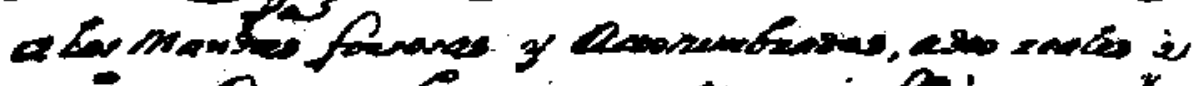

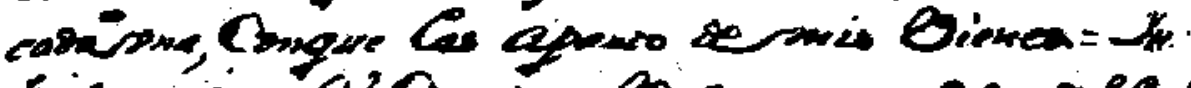

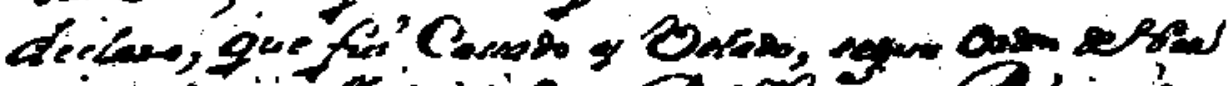

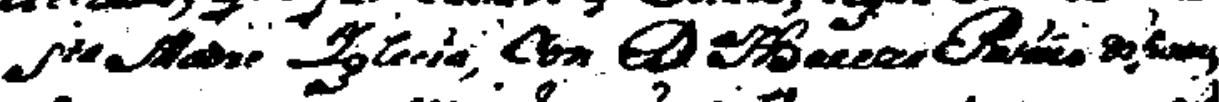

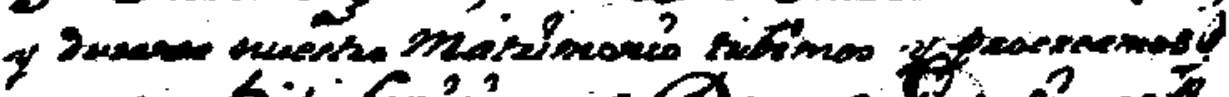

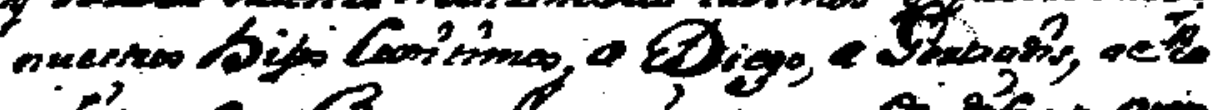

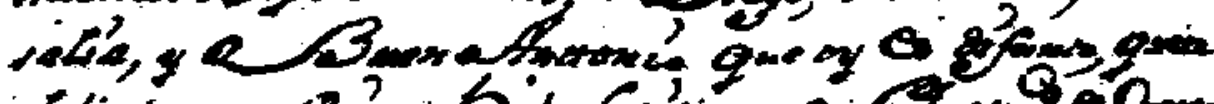

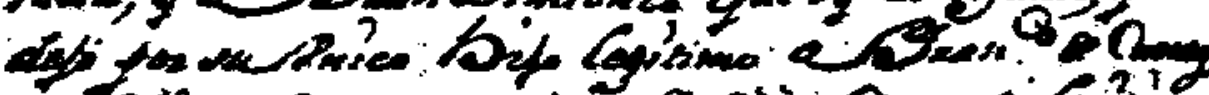

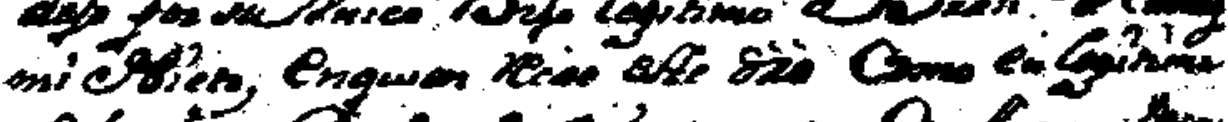

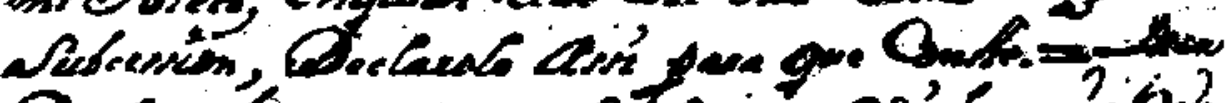

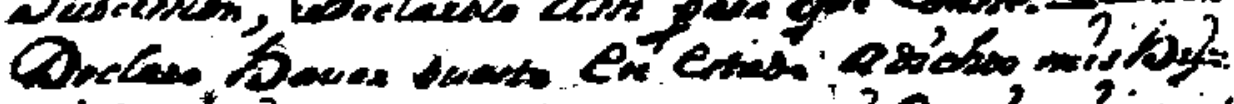

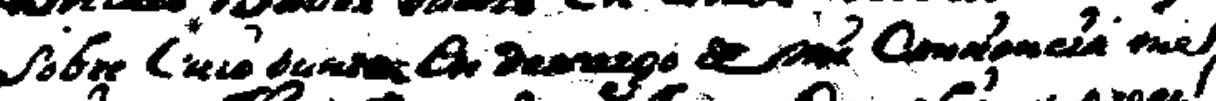

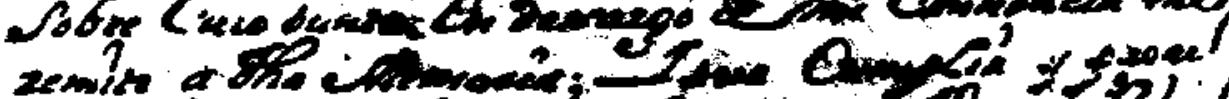

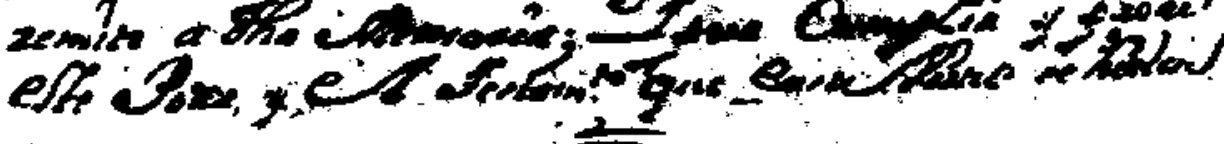




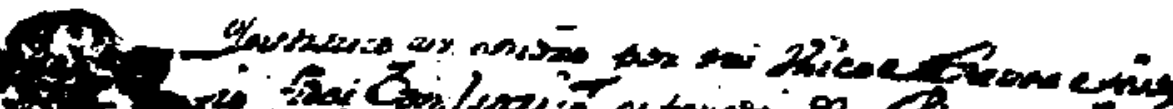

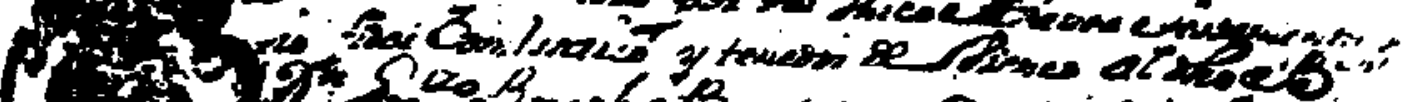

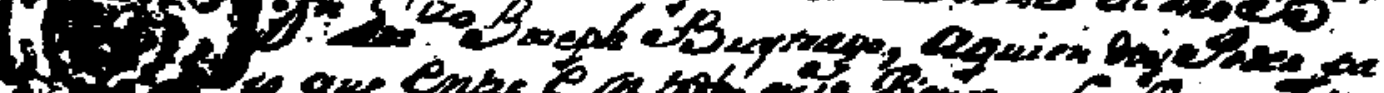

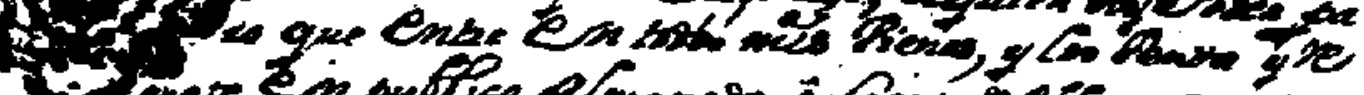

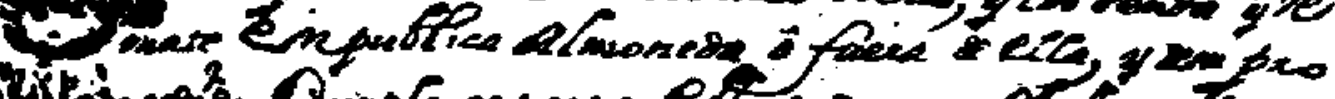

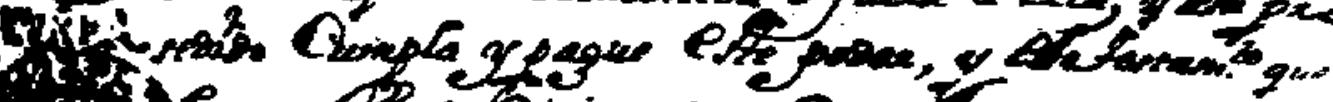

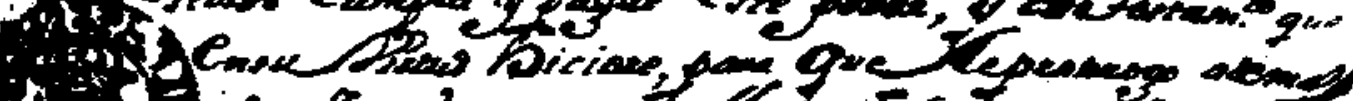

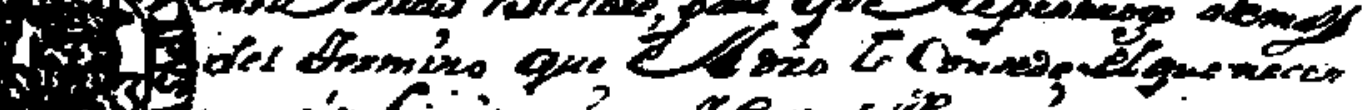

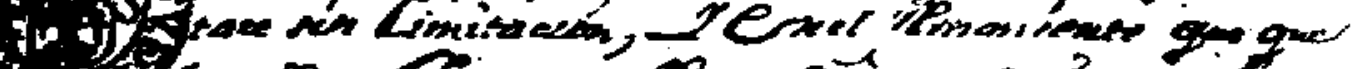

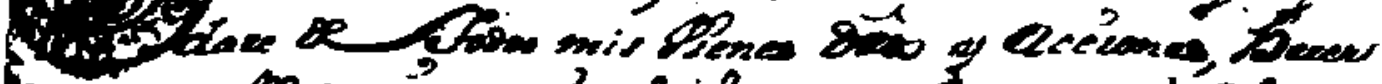

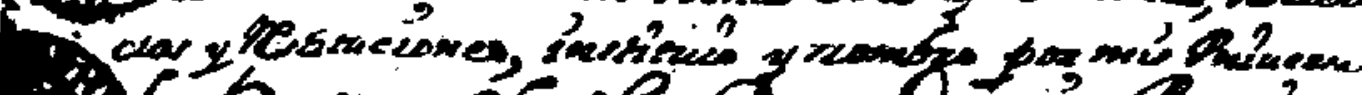

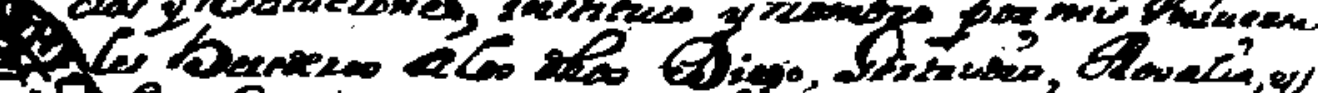

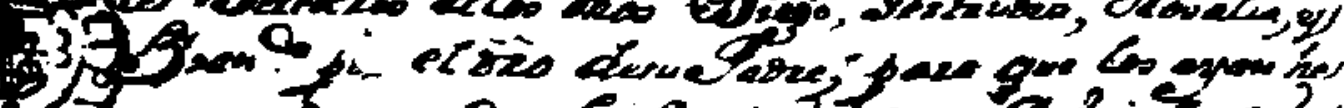

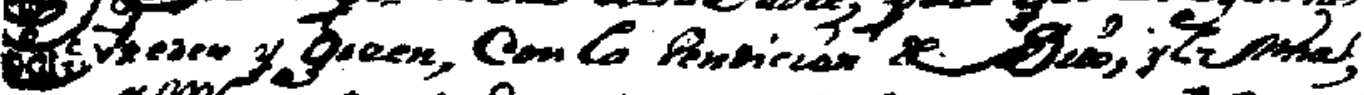

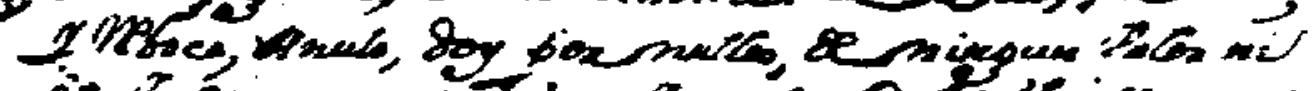

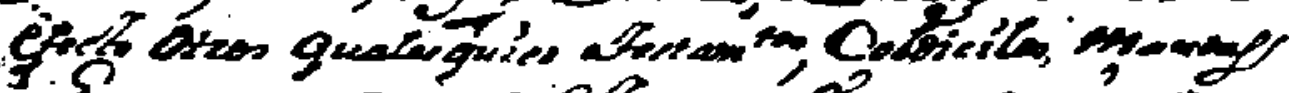

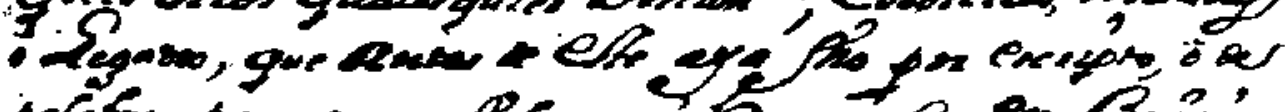

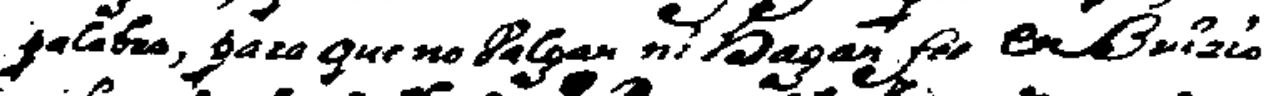

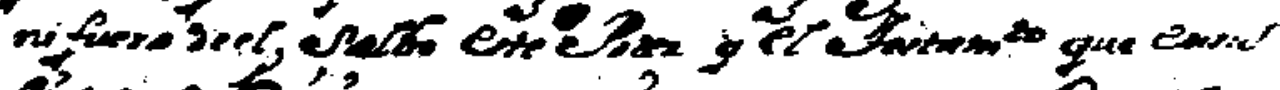

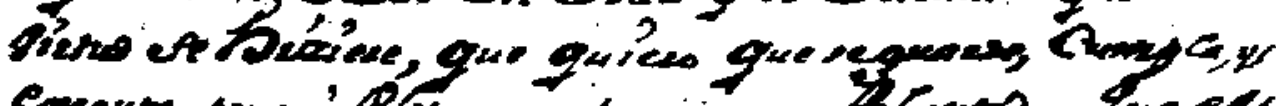

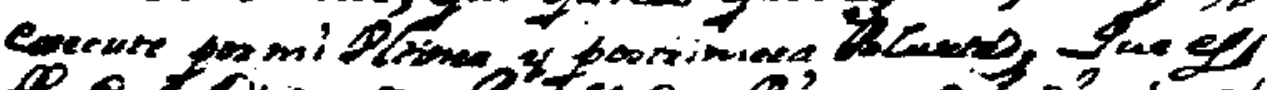

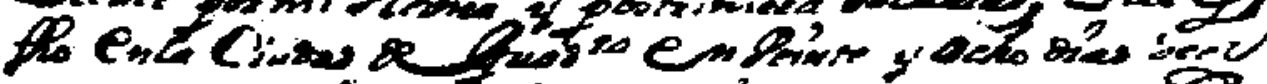

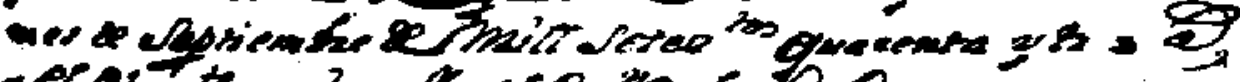

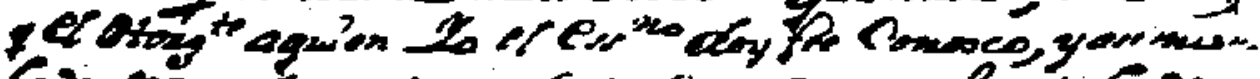

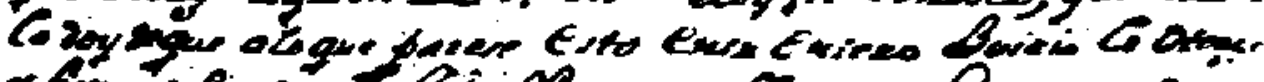

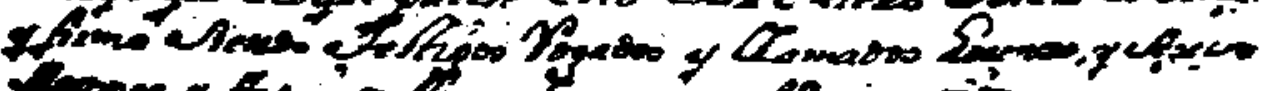

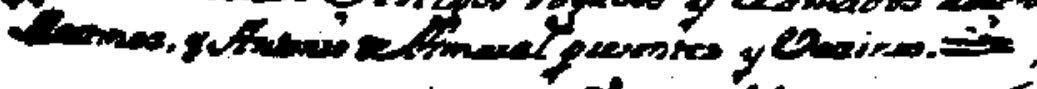

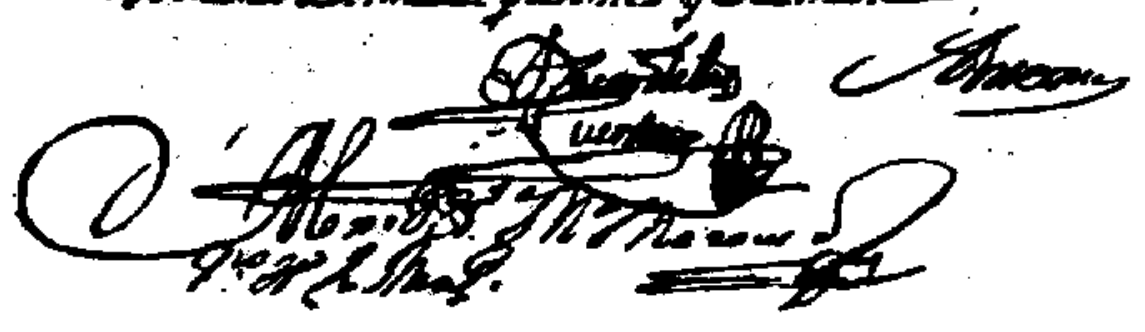




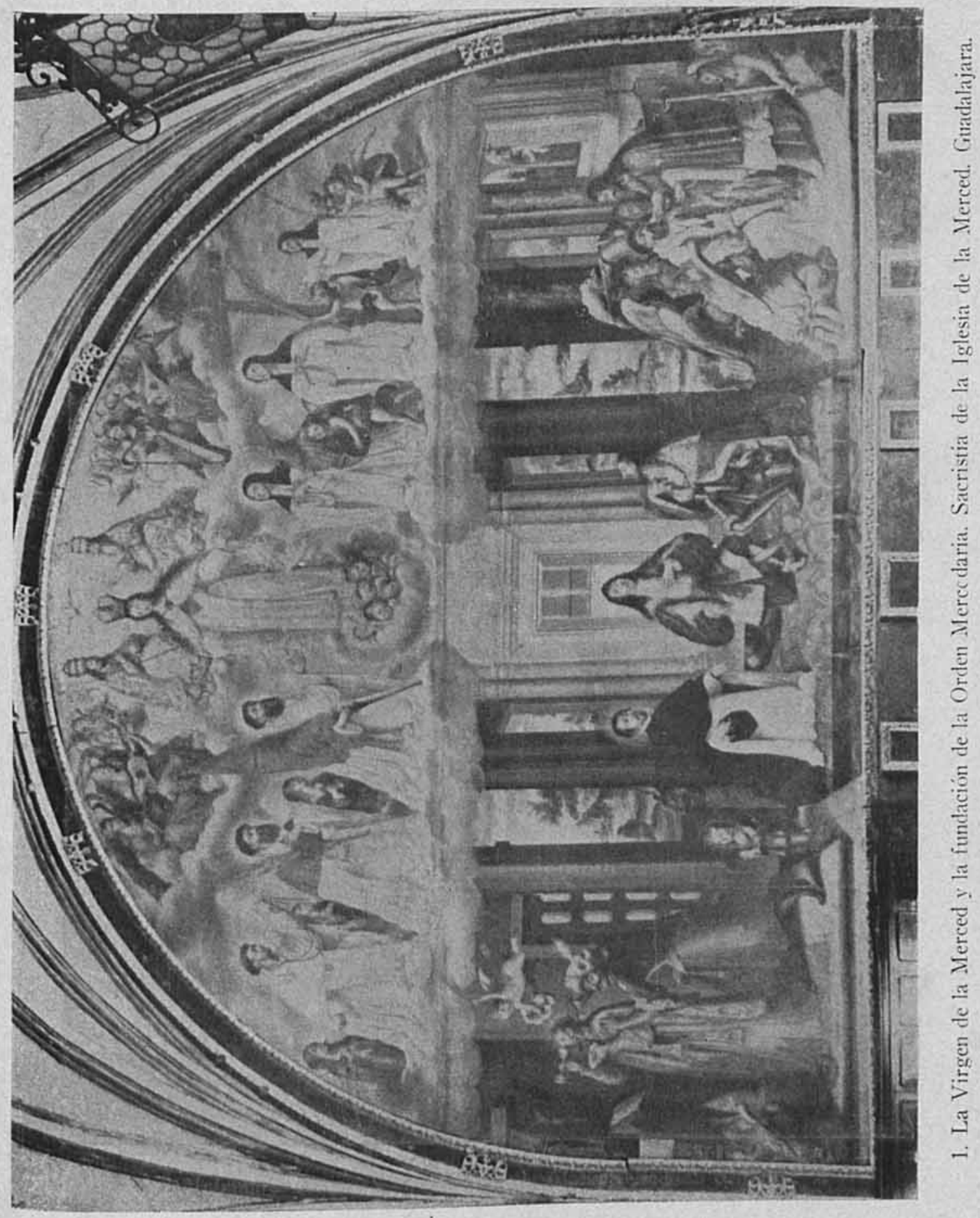




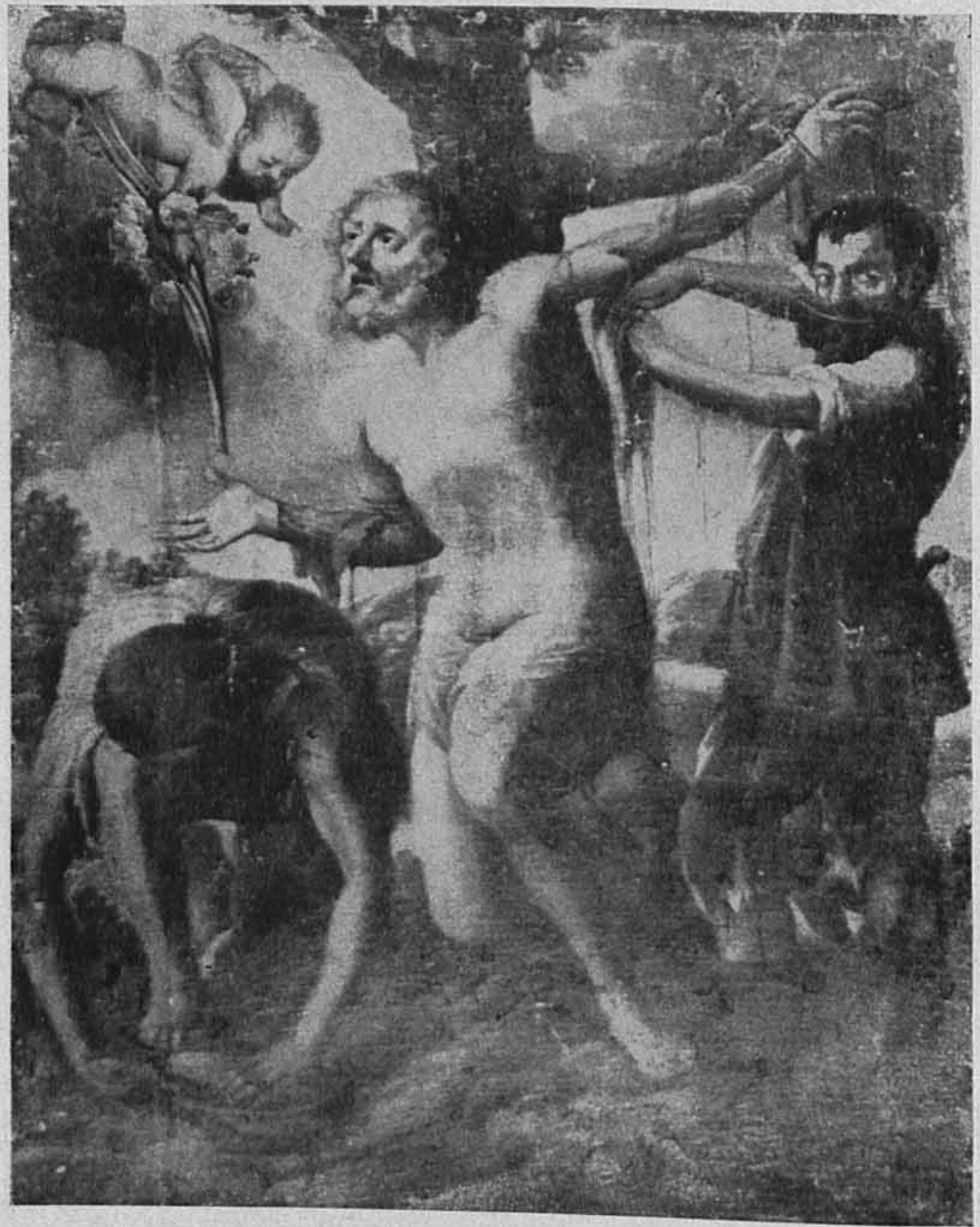

2. Martirio de San Bartolomé. Basilica de Zapopan. Guadalajara. 


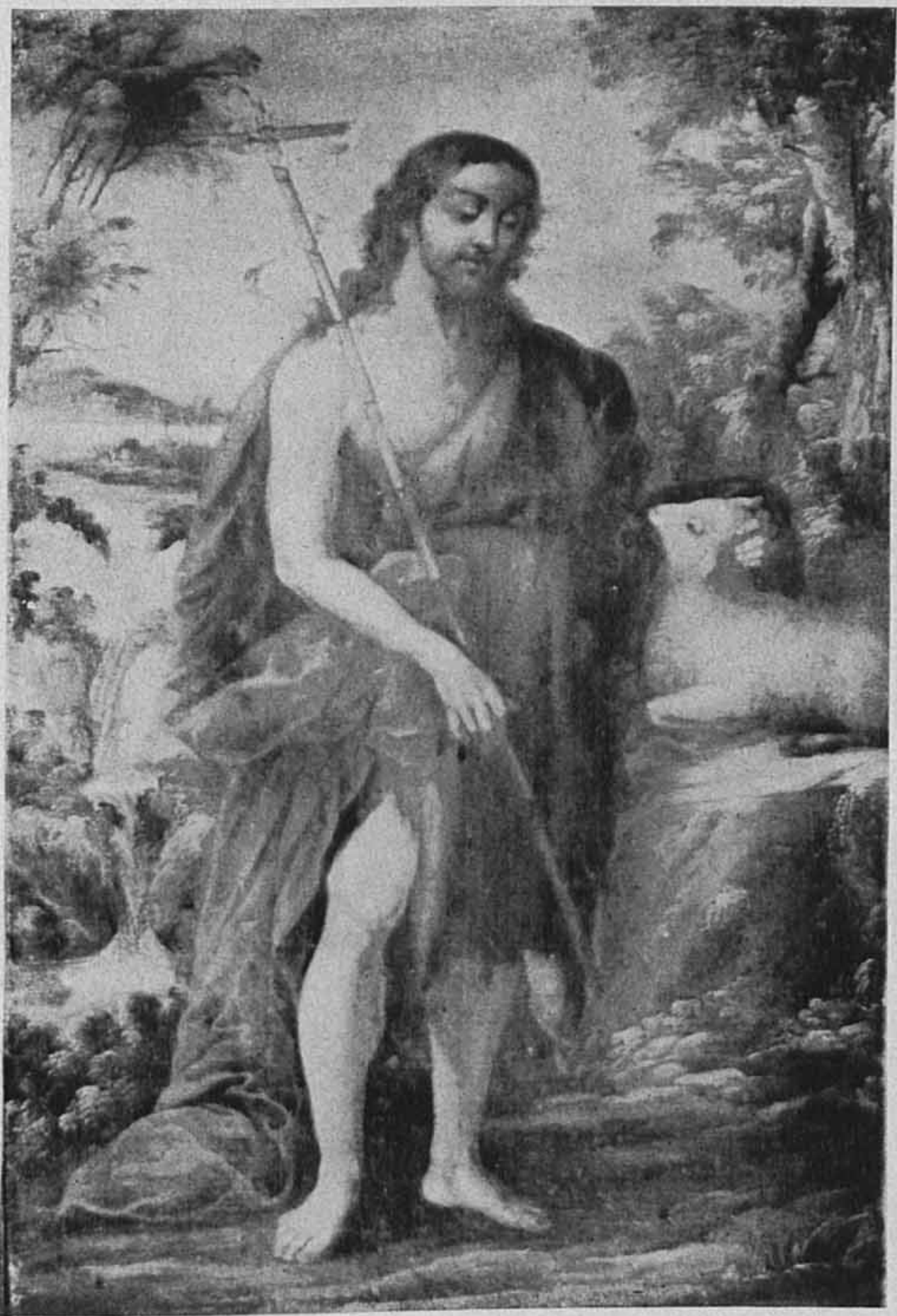

3. San Iuan Bautista. Colección particular. Guadalajara. 
DOI: http://dx.doi.org/10.22201/iie.18703062e.1951.19.520

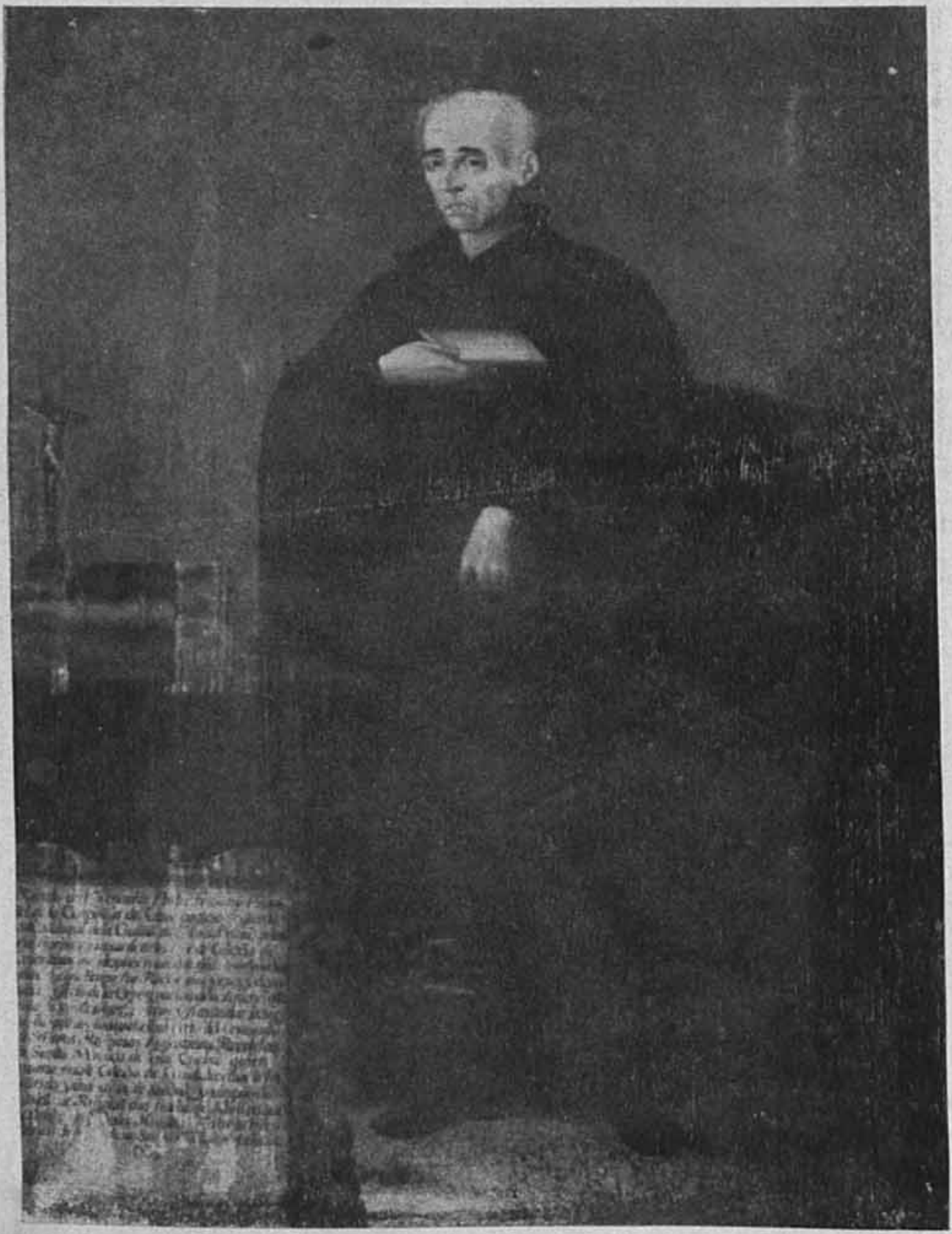

4. Retrato del P. Feliciano Pimentel. Catedral. Guadalajara. 


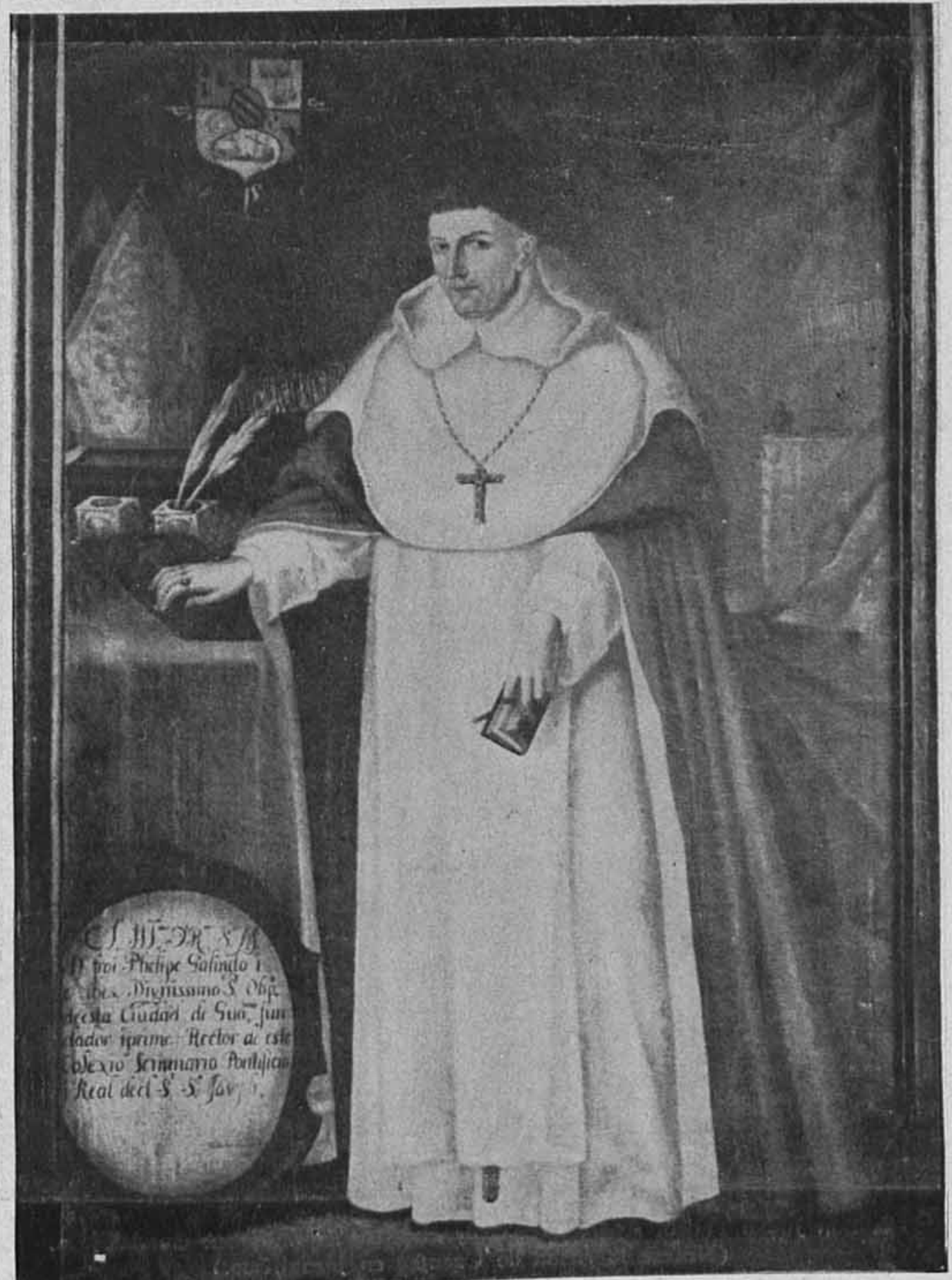

5. Retrato del obispo fray Felipe Galindo. Museo. Guadalajara. 


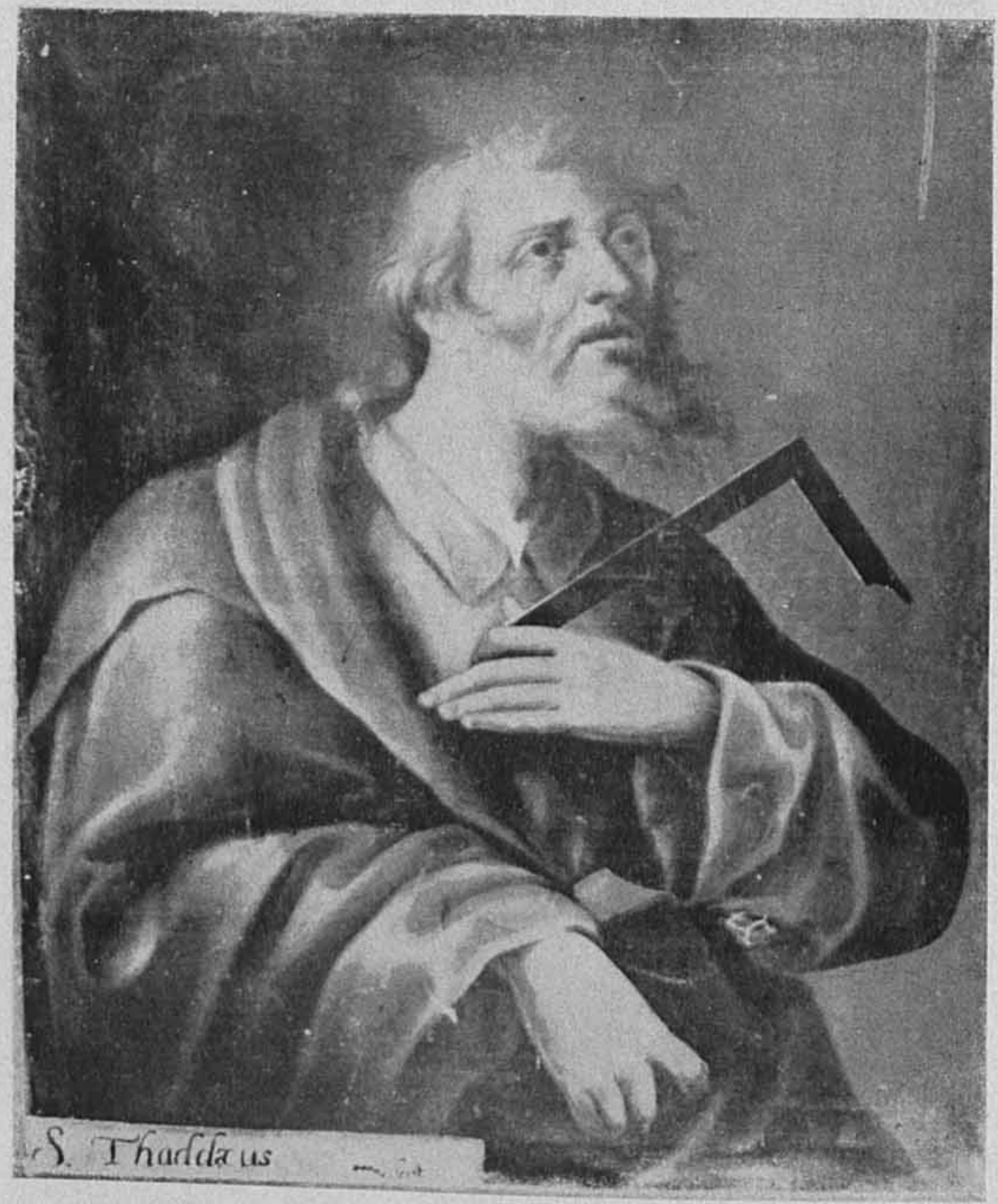

6. San Judas Tadeo. Apostolado de la Basiidea de Zapopan. Guadalajara. (Nótese la firma de Cuentas en jeroglifico.) 


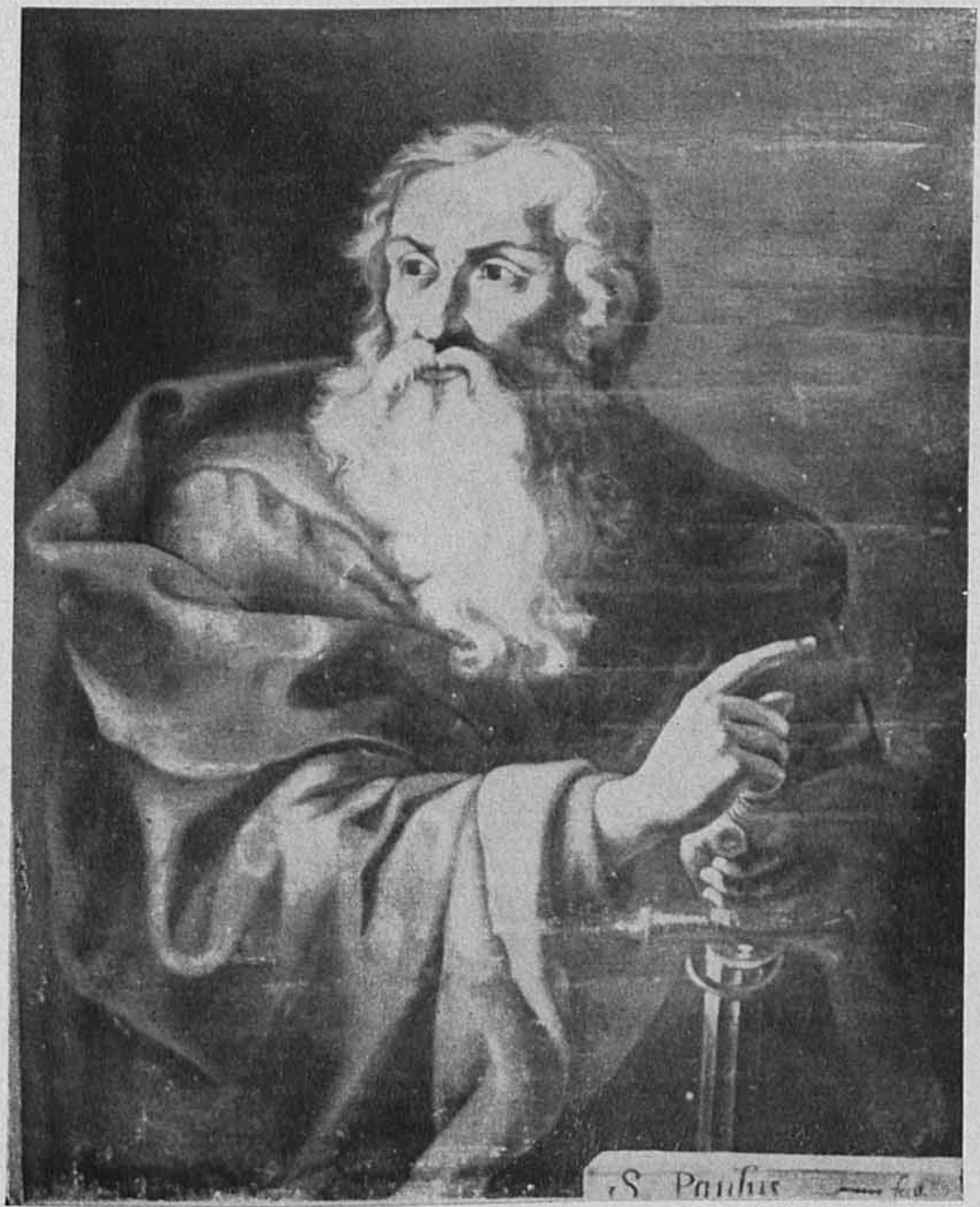

7. San Pablo. Apostolado de la Basilica de Zapopan. Guadalajara. 


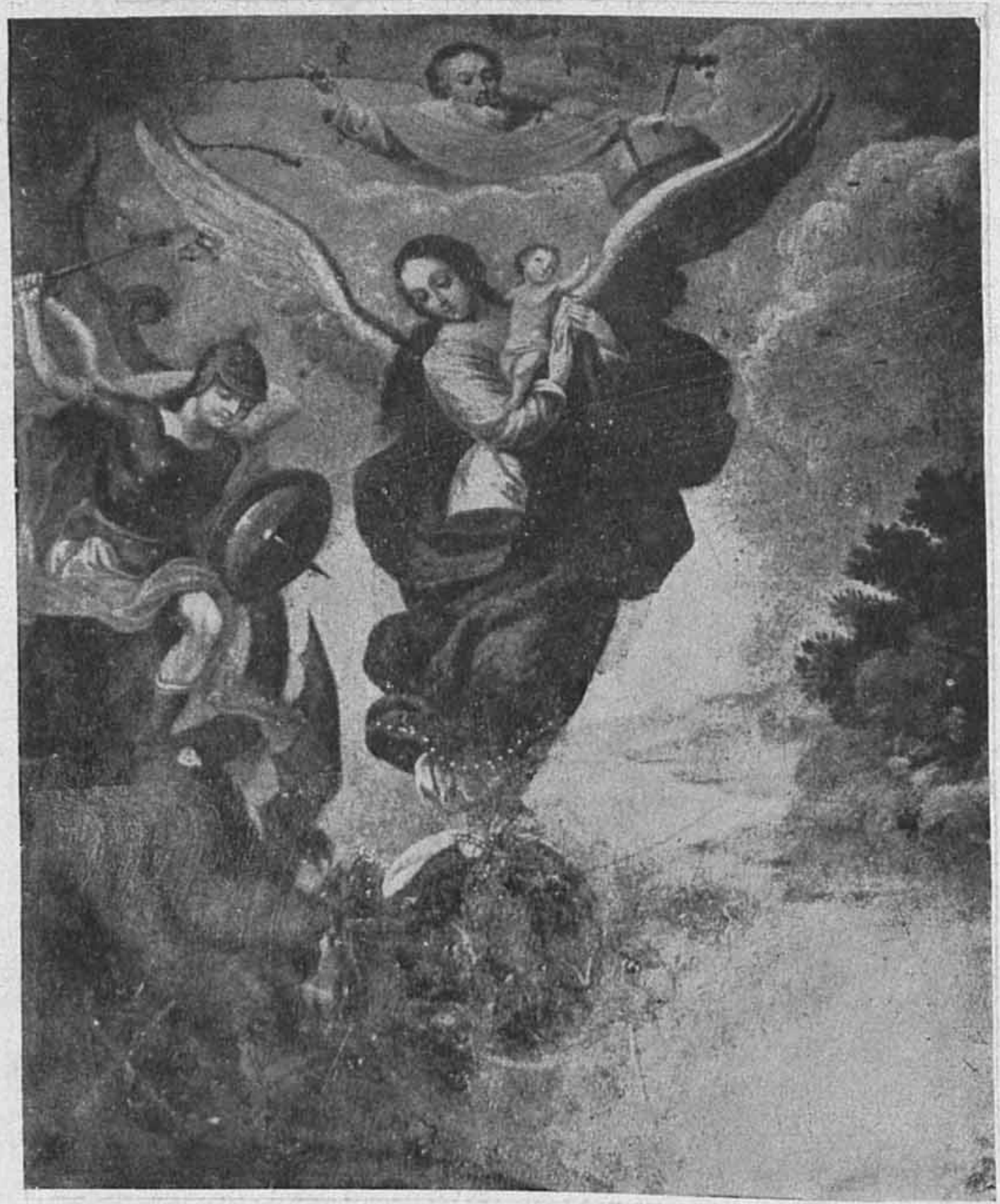

8. Virgen del Apocalipsis. Museo. Guadalajara, 


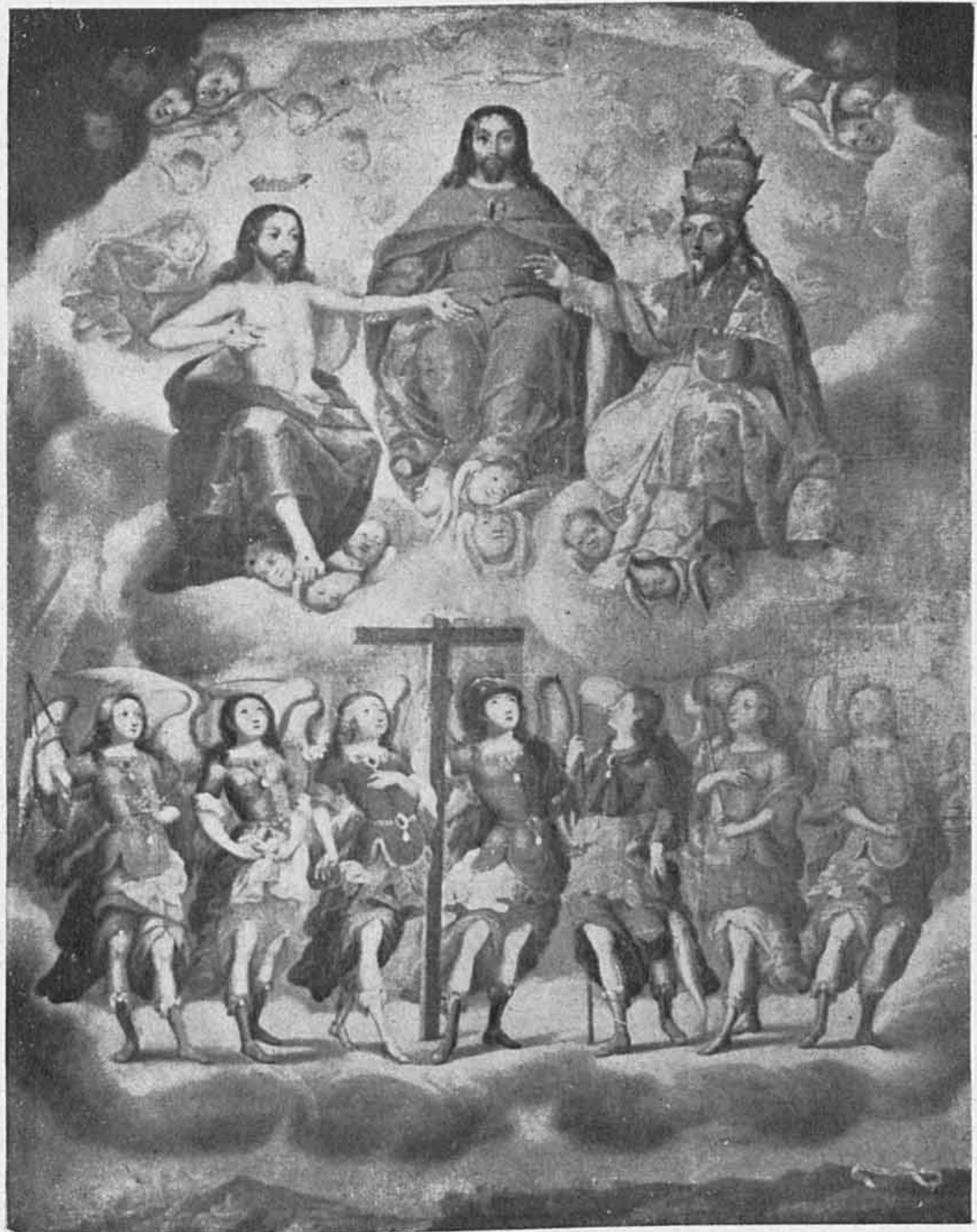

9. La Trinidad y los siete arcángeles. Museo. Guadalajara. 